\title{
EXPLORING LAND-SEA INTERACTIONS: INSIGHTS FOR SHAPING TERRITORIAL SPACE
}

\author{
Sue Kidd ${ }^{1}$, Dave Shaw ${ }^{1}$ (D), Holger Janssen ${ }^{2}{ }^{*}$ \\ ${ }^{1}$ Department of Geography \& Planning, University of Liverpool \\ Roxby Building, Chatham Street, Liverpool, L69 7ZT: UK \\ suekidd@liverpool.ac.uk•daveshaw@liverpool.ac.uk \\ ${ }^{2}$ Agency for Spatial Planning and State Planning Rostock Region \\ Landesbehördenzentrum, Erich-Schlesinger-Straße 35, 18059 Rostock: Germany \\ holger.janssen@afrlrr.mv-regierung.de
}

\begin{abstract}
The interactions between land and sea are fundamental to human wellbeing. Within Europe, the 2014 Directive establishing a framework for maritime spatial planning (MSP Directive), which requires EU coastal member states to have marine spatial plans in place by 2021, also requires that MSP authorities should explicitly take into account land-sea interactions. This has stimulated a new phase of investigation into land-sea interactions in Europe. This paper aims to contribute to marine and coastal planning debates by reflecting on one of these investigations, the Maritime Spatial Planning and Land Sea Interactions (MSP-LSI) project. The paper starts by providing a historical overview of the growing attention being paid to LSI within the context of European policy making. This sets the context for the MSP-LSI project and the approach to exploring land-sea interactions it developed is outlined. The paper then uses examples from the project's case study investigations to highlight and illustrate some of the wider insights the project revealed, both in relation to the extensive spatial footprint associated with selected maritime sectors and how marine space is being shaped by, and contributing to landward activity and governance agendas. It concludes by presenting a case not only for adopting a 'one space' perspective in MSP, but in territorial spatial planning and management regimes more generally.
\end{abstract}

Keywords: ESPON; governance; land-sea interaction; marine planning; territorial planning; value chain analysis.

\section{Introduction}

The interactions between land and sea are fundamental to human wellbeing. As the principles of ocean literacy reveal (OLC, 2013), the world's oceans, and life in the ocean, shape the features of Earth, act as major influences on its weather and climate, indeed make the Earth habitable and support a great diversity of life and ecosystems. In this way, oceans and humans are inextricably interconnected. Despite this, the oceans remains largely unexplored, but this situation is changing fast as growing global populations and economic growth are increasingly spreading development from the land to the sea and impacting on the health of the marine environment (UN, 2016) ). It is within this context that marine/maritime spatial planning (MSP) has emerged as an important new mechanism for guiding human development at sea (Zaucha \& Gee, 2019). Within Europe,

\footnotetext{
${ }^{*}$ This paper reflects the opinion of the author and does not necessarily represent government policy.
} 
MSP has been promoted through the 2014 MSP Directive (EC, 2014), which requires EU coastal member states to have marine spatial plans in place by, at the latest, March 2021. In doing so, the Directive also requires that MSP authorities should explicitly take into account land-sea interactions (LSI) (EC, 2014). This has stimulated a new phase of investigation into land-sea interactions in Europe which is highlighting afresh, both the complexity of land-sea relationships, and also, the extent to which human's landward activities and interests are increasingly shaping and intertwined with marine space.

This paper aims to contribute to marine and coastal planning debates by reflecting on one of these investigations, the Maritime Spatial Planning and Land Sea Interactions (MSP-LSI) project. This was a targeted analysis for the European Spatial Planning Observation Network (ESPON). Policy makers and stakeholders, drawn from across Europe, who share similar policy challenges, propose these targeted analysis projects. The commissioning of the research reflects the prominence of LSI issues among the European MSP community at the present time. The paper starts by providing a historical overview of the growing attention being paid to LSI within the context of European policy making. This sets the context for the MSP-LSI project and the approach to exploring LSI it developed is outlined. The paper then uses examples from the project's case study investigations to highlight and illustrate some of the wider insights the project revealed, both in relation to the extensive spatial footprint associated with selected maritime sectors and how marine space is being shaped by, and contributing to landward activity and governance agendas. It concludes by presenting a case not only for adopting a 'one space' perspective in MSP but in territorial spatial planning and management regimes more generally.

\section{MSP context and the importance of LSI}

Coasts, river catchments areas, and deltas have been of utmost importance for the development of humankind, economically and socio-culturally, for several thousand years (Glaeser, 2008). Coastal spaces provide people with manifold advantages, from diverse food sources to a diversity of livelihood and economic opportunities, as well as providing a setting for many communities to engage in long-standing traditional cultural and spiritual practices (Kannen et al., 2008). Interactions between the land and sea have thus been experienced by people for a long time and are now actively sought and used by them. From today's point of view, these interactions also include environmental impacts and biogeochemical cycles, as, especially in the last century, and continuing into this, coasts and seas have become more and more economically important, and are hence, exploited to the extent of being overused (Small \& Nicholls, 2003).

The question of which governance requirements arise from this situation is reflected by a debate that has lasted for decades. One of the first extensive discussions on the subject focused on Integrated Coastal Zone Management (ICZM). This began in the US in the 1970s and reached its climax in Europe around the turn of the new millennium (Shipman \& Stojanovic, 2007; Ballinger, 2015). As Cicin-Sain and Knecht (1998) argued, ICZM represented a new paradigm of management challenging existing management approaches, legal systems and administrative arrangements, particularly those being sectoral, discipline or problem-based. LSI were included in this new approach as an inherent part of the underlying concept of 'integration' with various dimensions of integration being categorized (Ballinger, 2015). These include inter-sectoral integration (amongst different coastal sectors), intergovernmental integration (amongst levels of government), spatial integration (including LSI), international integration (dealing with transboundary issues), and sci- 
ence-management integration (between disciplines and between science and management/policy). One of the earliest articulations of the importance of integration is from the text of "Agenda 21" adopted at the UN's Earth Summit in Rio de Janeiro in 1992, which established integration as a sought-after principle of sustainable resource management (Portman, Dalton \& Wiggin, 2015). This was felt to be particularly needed to address the challenging planning and management issues which were becoming increasingly apparent in coastal areas.

ICZM, at this point in time, tended to be focused on a narrow coastal strip. Sorensen and McCreary $(1990$, p.6), for instance, defined the space to be considered as "the band of dry land and adjacent ocean space (...) in which land ecology and use directly affect ocean space ecology, and vice versa." Similarly, UNEP (1995) defined the 'coastal area', being subject for an ICZM management, as a belt about nine miles wide. Furthermore, much of the ICZM effort had been through mostly, informal bottom-up, local initiatives (Smith et al., 2011).

In the further course of the debate, a UNESCO-IOC initiative started in the early years of the $21^{\text {st }}$ century contributed to a shifting of the focus towards more formalized and marine orientated planning in order to help to manage the ever-increasing pressure to use the sea (UNESCO-IOC, 2019). The initiative was significant in raising international awareness of MSP through international workshops, the publication of a handbook (Ehler \& Douvere, 2009) and publication of numerous papers on the topic (e.g. Douvere \& Ehler, 2007, 2008, 2009a, 2009b; Ehler \& Douvere, 2007a, 2007b). MSP is now, almost always, described as 'integrated', even if coastal up-lands, were especially in the early years of MSP, often left out of the planning process (Portman et al., 2015).

Driven by these international discussions, as well as by the understanding that increasing marine and maritime activities may require a more comprehensive marine management, a number of coastal nations started to extend terrestrial spatial planning regimes into their seas. In doing so, it became quickly apparent that terrestrial planning and MSP exhibited a variety of differences (Kidd \& Ellis, 2012) and that the introduction of MSP caused some challenges. One of these challenges is the question of 'how to deal with LSI?' While Ehler and Douvere $(2009$, p.62) only reminded planners, in a very abstract way, that an "[MSP] management area typically is affected by human activities that are: (1) upstream from the marine management area, (...); and (2) downstream from the marine management area (...)", Shipman and Stojanovic $(2007$, p.389) already warned that a new 'Coastal Squeeze' could occur as governments turned "their attention to the planning and management of the marine zone as an entity, while the boundaries of terrestrial administrations and their spatial plans remain rigidly limited to the tide-line".

In Europe, such concerns were taken seriously, when the European Commission, in March 2013 presented a draft of a Directive for establishing a framework for maritime spatial planning and integrated coastal management. At this time, the two topics (ICZM and MSP) were packaged together into a single directive, which would have obligated member states to prepare strategies for ICZM along their coastlines, in addition to maritime spatial plans. However, it was not possible to make such legislation binding. Under the European Union's existing legal structures, policy areas such as land-use planning, property rights and building permits were, and remain, an exclusive competence of the member states. The majority rejected extending a competence of the European Commission into these policy areas.

This debate finally resulted in the European MSP Directive (EC, 2014). This requires member states to have in place Marine Spatial Plans, though is less prescriptive on their form and character. Indeed, instead of giving detailed binding stipulations this directive now requests that states' "shall take into account land-sea interactions" but provides little advice or guidance on how to do this. It was in this context that the MSP-LSI ESPON targeted analysis was framed. 


\section{MSP-LSI project approach}

As can be seen from the above, the MSP Directive's reference to LSI reflects understanding that has built up over many years. In addition to the ICZM experience, this understanding reflects a growing body of scientific research, associated, for example, with the Land-Ocean Interactions in the Coastal Zone project which was established in 1993 as a core element of the International Geosphere-Biosphere Programme (Ramesh et al., 2015; FEC, 2018), as well as findings from influential United Nations' reports, notably the Millennium Ecosystem Assessment (UNEP, 2006) and the First Global Integrated Marine Assessment (UN, 2016). Running alongside these mainly environmentally focussed initiatives there has also been mounting evidence of the significance and potential, of the 'Blue Economy' in contributing to global development agendas (e.g. EC, 2019). Taken together, this information has not only provided much of the impetus for establishing MSP systems in Europe, and elsewhere, but it has also provided a rational for seeing MSP as a natural focus for LSI considerations going forward. It has been the spur for a new generation of LSI investigations, exploring the role that MSP can play in addressing LSI.

Table 1. Some Selective Key European Studies related to LSI and MSP

\begin{tabular}{|l|l|}
\hline 2013 & European Seas Territorial Development Opportunities and Risks (ESTaDOR) (University of Liverpool, 2013) \\
\hline 2016 & Study of Conditions of Spatial Development of Polish Sea Areas (SCDS PL, 2016) \\
\hline 2017 & Addressing LSI in MSP (EU MSP, 2017a, 2017b) \\
\hline 2018 & $\begin{array}{l}\text { Supporting Maritime Spatial Planning in the Eastern Mediterranean (SUPREME), Supporting } \\
\text { Implementation of Maritime Spatial Planning in the Western Mediterranean (SIMWESTMED) (Ramieri, } \\
\text { Bocci \& Marković, 2018) }\end{array}$ \\
\hline 2019 & $\begin{array}{l}\text { Implementing the source-to-sea approach (Matthews et al., 2019) } \\
\text { Approaching LSI in Pan Baltic Scope (Morf, Cedergren, Gee, Kull \& Eliasen, 2019) } \\
\text { (Soupporting Implementation of Maritime Spatial Planning in the Northern European Atlantic (SIMNORAT) }\end{array}$ \\
\hline 2020 & Maritime Spatial Planning and Land Sea Interactions (MSP-LSI) (Kidd et al., 2020) \\
\hline
\end{tabular}

Source: own elaboration.

Europe has been a hotspot for these investigations. Table 1 provides an illustrative overview of some of the key recent LSI studies.

While there have been preliminary efforts to draw related researchers and practitioners together to reflect on and disseminate findings (see e.g. EU MSP, 2017b), there is great scope to build upon experience developed thus far and explore future research and practice directions. The remaining discussion, drawn from of some of the insights and their wider implications arising from the MSP-LSI project, has been written with this in mind.

The MSP-LSI project investigated how LSI considerations could be defined and operationalized for the MSP community, with a particular focus on LSI associated with the maritime sectors. The overall concept underpinning the MSP-LSI approach (illustrated in Fig. 1) reflects a 'one space' territorial panning planning perspective designed to enable:

- coordinated, comparable, systematic definition and evidence-based analysis of critical LSI dimensions of relevance to MSP and those engaged in terrestrial planning and management across Europe; 


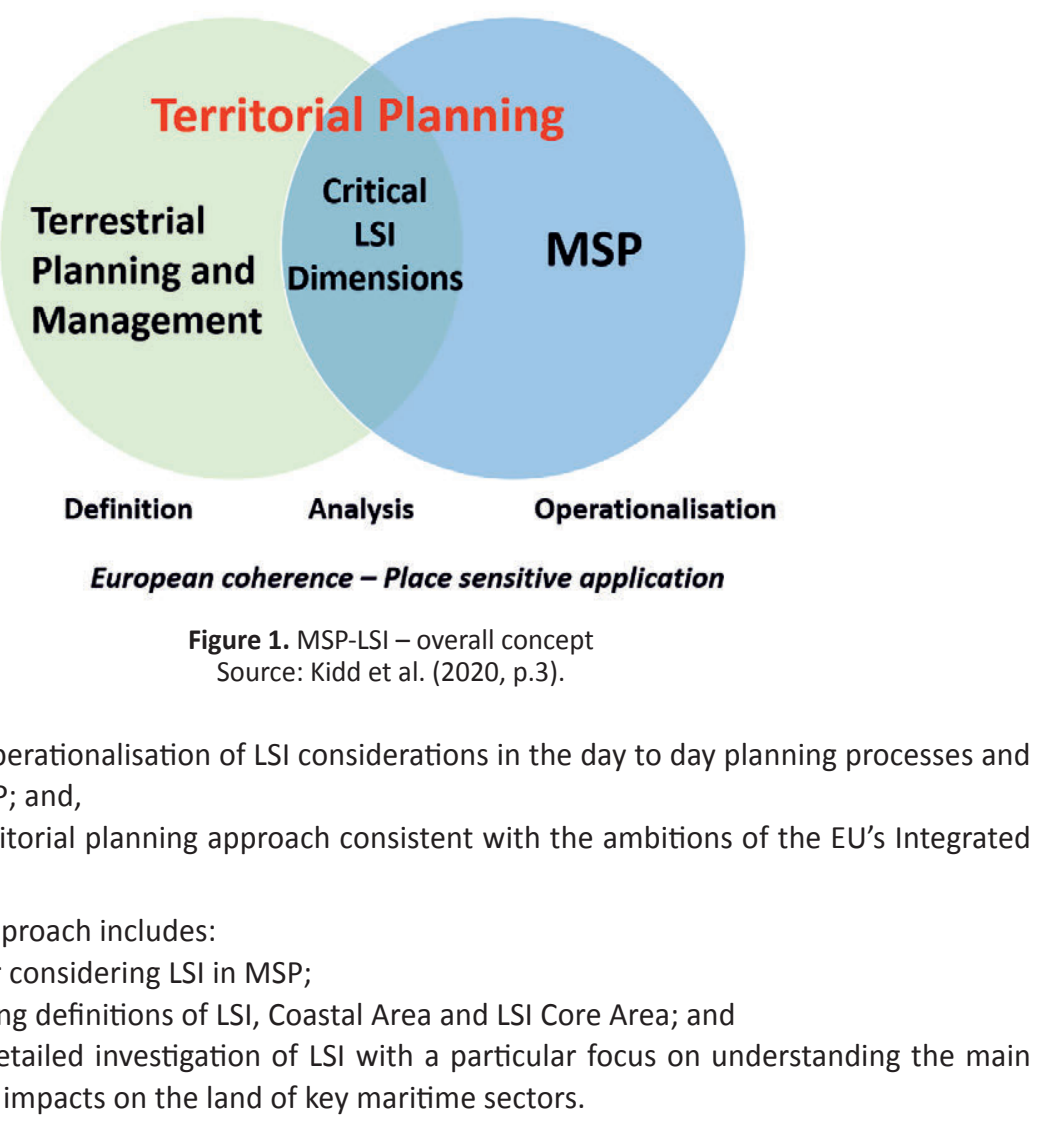

- place specific operationalisation of LSI considerations in the day to day planning processes and practices of MSP; and,

- a joined-up territorial planning approach consistent with the ambitions of the EU's Integrated Maritime Policy.

The MSP-LSI approach includes:

- a framework for considering LSI in MSP;

- proposed working definitions of LSI, Coastal Area and LSI Core Area; and

- a method for detailed investigation of LSI with a particular focus on understanding the main socio-economic impacts on the land of key maritime sectors.

\section{A framework for considering LSI in MSP}

The framework for considering LSI in MSP (see Fig. 2) drew upon inputs from recent European LSI research/practice including work undertaken by/for the European MSP Platform (EU MSP, 2017a, 2017b), DG Environment (EC, 2017), the SUPREME and SIMMEDWEST projects in the Mediterranean (Ramieri et al., 2018), the Pan Baltic Scope project in relation to the Baltic Sea (Morf et al. 2019), and by the Dutch Government for their area of jurisdiction in the North Sea (PDNS, 2015). It illustrates that LSI encompass complex and dynamic interrelationships between socio-economic activities, bio-geochemical processes and governance arrangements on both the land and in the sea. It also provides a list of LSIs which have previously been identified as being of potential relevance to MSP, although the relative importance of each will be place specific.

\section{Defining LSI}

The framework is intended to provide an initial reference point for exploring LSI in different contexts. Complementing this, working definitions of key related terms - LSI, Coastal Area and LSI Core Area - were also put forward both as prompts for discussion at an early point in LSI investigations and to help deepen understanding of LSI and associated issues as they relate to specific areas (Table 2). See Box 1 


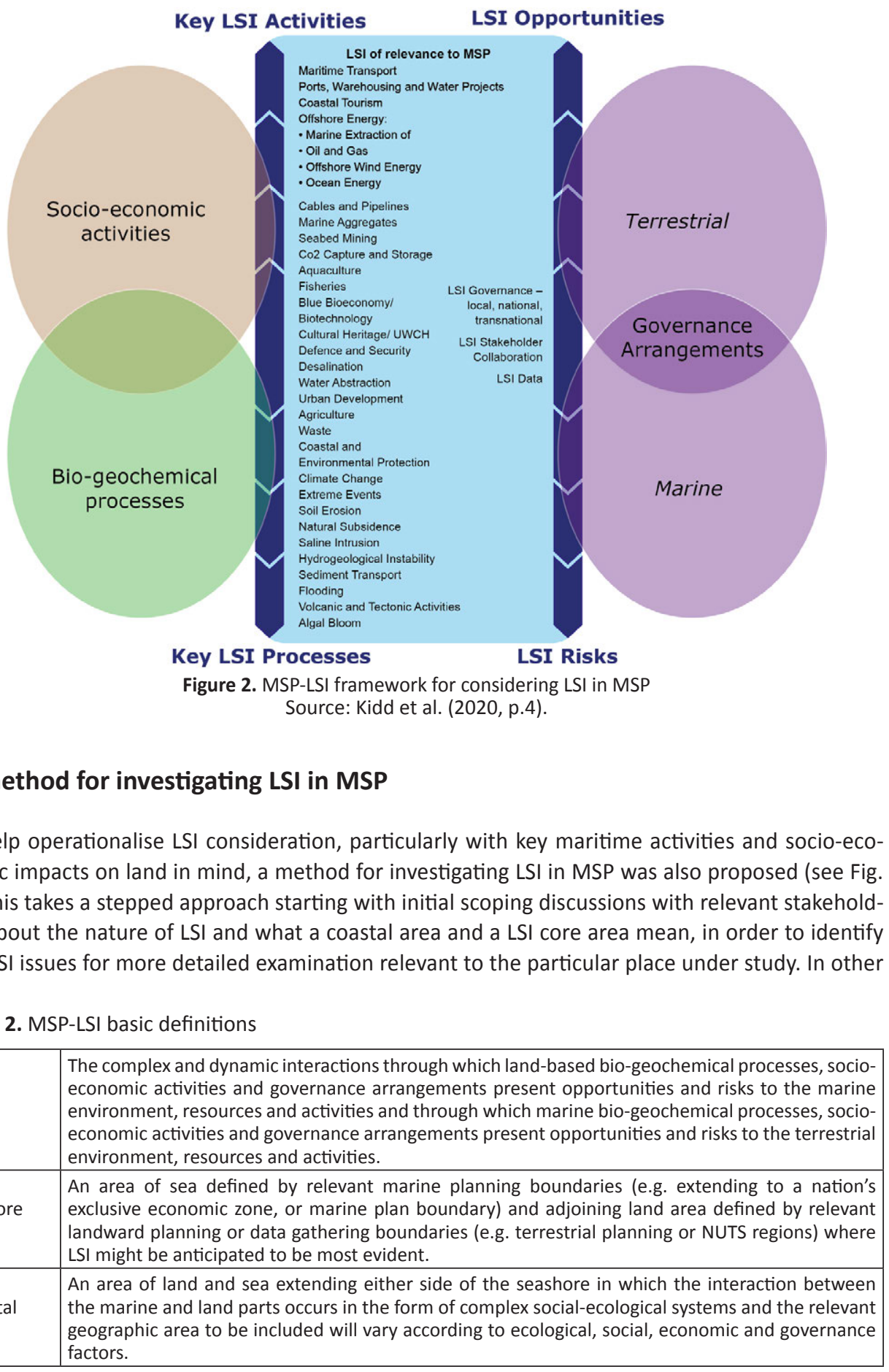

Source: Kidd et al. (2020, p.5). 
words, the method recognises the scope to narrow and focus the debate to selective LSI issues to make the investigation more manageable and meaningful. For LSI associated with maritime sectors, the project then elaborated a spatialized form of value chain analysis based around established value chains used by the World Trade Organisation, and others, to investigate backward and forward economic linkages associated with different economic sectors and the 'framework conditions' impacting on the performance of that activity in different contexts (Fig. 4). For territorial planning purposes, elaborating the spatial footprint associated with different segments of the value chain was considered to be a valuable extension of established, largely aspatial approaches. This was developed to inform discussions about related space and infrastructure requirements and the relative distribution of socio-economic benefits including the potential 'stickability' of benefits and leakages for coastal communities. In addition, the MSP-LSI project outlined a structured governance analysis covering both a general overview of LSI responsibilities and coverage in marine and terrestrial plans and a consideration of governance associated with selected LSI issues. As a final step it is suggested that the findings from these different aspects of investigation are brought together to draw out key messages and recommendations for good management of LSI in MSP and more widely.

The method described above was tested and refined through five pilot case studies (in Slovenia, the Gulf of Gdańsk, the Croatia Coast and Islands, The Pomeranian Bight and Dutch North Sea). These provided interesting examples, not only of the application of the method in different contexts, but also of the type of LSI insights that such analysis can provide and how these might inform MSP and wider territorial planning agendas.

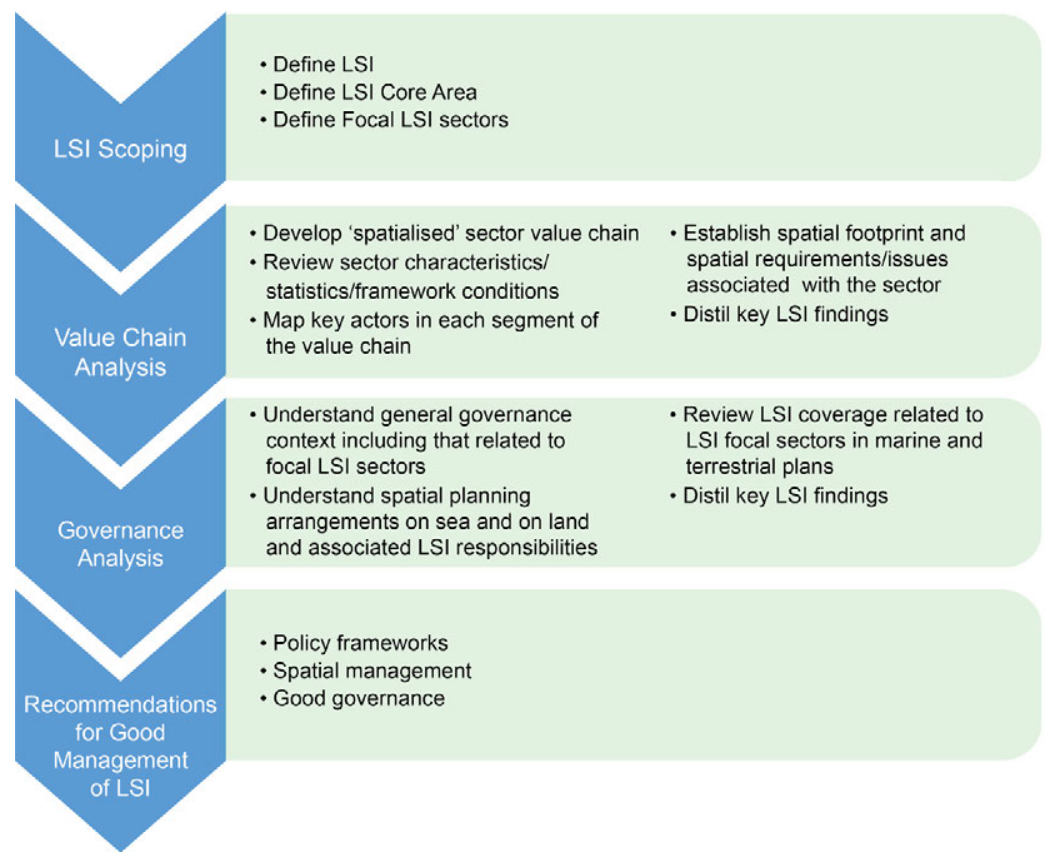

Figure 3. A method for investigating LSI in MSP Source: Kidd et al. (2020, p.6). 


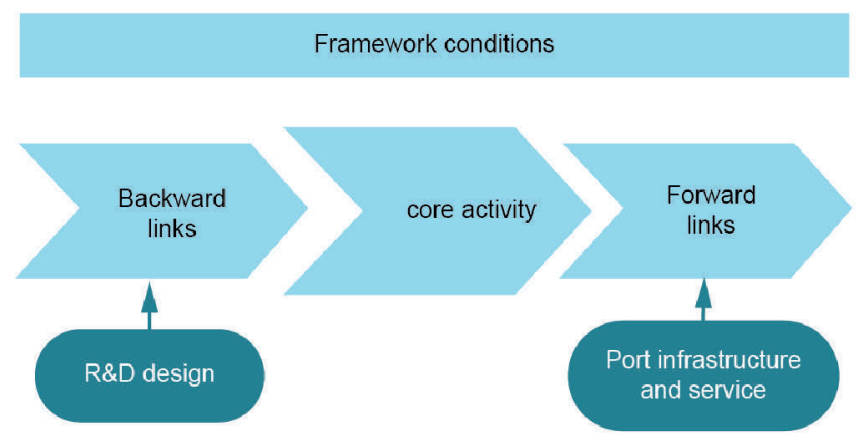

Figure 4. Maritime sector value chain analysis Source: Ecorys (2012, p.14).

\section{LSI insights and territorial planning agendas}

\section{Insights from the value chain analysis}

Perhaps the most immediately striking observation from following the different segments of maritime sector value chains is that in all the cases examined their spatial footprint extended well beyond the sea and adjoining coastal areas. Indeed, mapping of key value chain actors, in all instances, revealed a transnational spread of activity and connections, including many of a global nature. In this sense, the MSP-LSI project confirmed the appropriateness of the MSP Directive including the open and geographically wide-ranging concept of LSI as a focus of MSP investigation rather than the potentially more narrowly conceived concept of ICZM.

The international footprint of maritime sectors was predictably most evident in the study of maritime cargo transport value chains, as $74 \%$ by volume and $50 \%$ by value of goods entering or leaving Europe do so by sea, and it is at coastal ports that the transition between the land and sea occurs. As a consequence, European ports operate in a highly competitive global logistics market and in the case study areas, an overarching national priority was to invest in new port and associated inland infrastructure to maintain, or to increase, their share of shipping activities and to respond to environmental concerns. The value chained analysis revealed ports as key nodes within complex global logistics networks. In the Netherlands, Rotterdam, the busiest port in Europe, handling $15.2 \%$ of all Europe's inbound and outbound cargo is knitted in to logistics connections that have associated space and infrastructure requirements at national, European and transnational scales. Similarly, in Poland, the ports of Gdynia and Gdańsk are important not only for the Polish economy, but provide a gateway to the whole of the Baltic Sea area. They are also key points in transnational logistics corridors that connect to the Adriatic and beyond.

Even in maritime sectors such as mariculture, which may be more artisanal in character and scale, the international reach of associated value chains can be evident. In Slovenia, where expansion of mariculture was supported by government partly as a response to its declining fishing industry, associated activities including production, processing and some consumption are very much focused at the coast and are of local significance. However, the value chain analysis revealed that supplying markets well away from the coast, in the national capital Ljubljana and in Italy and Austria, were also important to the well-being and operation of the sector with easy transport ac- 
cess to these destinations regarded as vital for such highly perishable product. Understanding the extensive spatial reach of maritime sector activities, therefore, begins to highlight the need to not simply focus on the activities undertaken in marine and coastal areas for planning purposes, but also to recognise that the wider networks of activity may require wider planning responses as well.

A logical extension of this finding is that the socio-economic benefits associated with maritime sectors are widely spread among landward communities. This understanding raises questions about the relative 'stickability' of benefits, such as the extent to which sector related employment opportunities are located in the coastal areas, and how local retention of such benefits can be maximized. It also raises questions about the tradeoffs that MSP and other regulatory regimes may need to reflect upon in balancing national and international interests with those of coastal communities, especially in situations where the convergence and intensity of activities at the land-sea interface may create potential conflicts.

Such considerations were highlighted, for example, in the Slovenian case study with its small, strategically important and intensively used coastal and marine area. Here expansion of the Port of Koper is identified as a national imperative, but this raises questions about potential conflicts with coastal stakeholders and their priorities. With the coastal economy based predominantly around coastal tourism, maintaining a high-quality local environment is considered as critical to ensure the future sustainability of this industry. Local stakeholders were therefore concerned that increased shipping might increase marine disturbance and the threat of pollution because of accidents, which in turn might compromise the tourism offer.

The case study examination of offshore wind energy production, similarly, raised the need for careful consideration of the spatial distribution of socio-economic benefits associated with maritime sector activities. Like maritime cargo, offshore wind energy is increasingly being seen as nationally significant sector in western and northern parts of Europe, due to its role in the transition to a low carbon economy. In Germany, there is a national imperative to decarbonize energy production and offshore wind energy is seen as offering great potential, to not only contribute to this agenda, but also provide a significant number of jobs. By taking a spatialized approach to the value chain analysis, where the winners and potential losers in this agenda are located becomes evident. In the Pomeranian Bight, which was one of the case study areas, offshore wind energy development is in its infancy. In Poland, the Marine Spatial Plan of the Polish Sea Areas recognises the potential of this new activity although no schemes have yet been developed, whilst in Mecklenburg-Vorpommern (Germany) three schemes have been commissioned by the Lander and the Bund. However, a spatial analysis of the value chains shows that many of the jobs are likely to be created far away from the coast. The Saarland region is for example a key source of high-quality steel for the foundations of wind turbines, while North Rhine-Westphalia, Bavaria and Baden-Württemburg are the main German benficiaries of the expansion of offshore wind power, with $50 \%$ of the turnover and $40 \%$ of the employees in the industry in Germany coming from these three federal states. Furthermore, communities who live a considerable distance from the coast consume most of the energy produced. By contrast coastal communities have concerns regarding offshore wind farm developments, because they perceive that they could adversely affect the local economy with its emphasis on tourism and the intrusion of new infrastructure in what have traditional been unrestricted seascapes. Thus, they perceive the coastal community may suffer a disproportionate disbenefit from a collective national good. In this way, value chain analysis can help to tease out the distribution of socio-economic benefits between different communities and in so doing aid decision making. 
Finally, the spatialized value chain analysis is significant in revealing that maritime sector related activities tend, overall, to be predominantly land, rather than sea based, with often few value chain segments requiring sea space. This serves to underline the importance of an integrated territorial planning and management perspective encompassing not only the marine elements but also landward elements, such as those required for transportation infrastructure, which may be central to the maritime sectors operation, success and sustainability. For example, in Poland, with the ports of Gdynia and Gdańsk, space in the sea has been reserved in the Marine Spatial Plan of the Polish Sea Areas so that further seaward extension of the port infrastructure can be enabled, but most of the need to renew and extend the infrastructure, to move goods to and from the ports, are land based. Similarly, with the port of Rotterdam, in the summer 2018, because of drought conditions, many of the connecting inland waterways became unnavigable. This has led to a growing understanding that if such conditions become increasingly common, then there will be a need to rethink how goods are transported to and from the port. This transport infrastructure is predominantly land based and there may also be a need for new logistics facilities, as patterns of transhipment change, all of which require space. In both these cases, MSP on its own has relatively little scope to address such issues, emphasising the importance of taking a 'one space' territorial perspective.

\section{Insights from the governance analysis}

The governance analysis, an important second strand in the MSP-LSI approach, also produced some intriguing insights. These arose from both a consideration of governance arrangements associated with individual maritime sectors as well as from an examination of the legal and policy frameworks related to spatial planning more generally. In many cases, it was the interplay between these two aspects that shaped the LSI in different contexts.

Findings from the maritime sector governance analysis were particularly notable in pinpointing the place of MSP within the wider governance architecture influencing the performance and development of the maritime economy. In all the sectors and case study areas examined, it was evident that sector related policies at international, national, regional and/or local scales tended to be the key governance drivers and that spatial planning on land and for the sea played a supporting rather than leading governance role. Having said this, three important roles for MSP (and indeed spatial planning more generally) were identified, the significance of which should not be understated. The first relates to providing a marine policy framework which is supportive of sectoral policy agendas. This requires MSP to coordinate with sectoral governance regimes and to act as a key stakeholder providing seaward and placed based perspectives to sectoral policy development and an agency of sector policy implementation. The second role relates to spatial management. This can be delivered through designating space in marine plans for seaward elements of sector activity, and by reflecting on sectoral interests in assessing individual marine licensing decisions, which may directly or indirectly impinge on sector performance and development. Thirdly, and arguably most significantly, MSP has a good governance role. Through the development of marine plans (and sometimes through consideration of individual license applications) MSP provides a rare opportunity for place-based discussions about maritime agendas. This activity can bring together stakeholders from a wide range of interconnected communities of interest to engage with maritime issues which, in normal circumstances, may receive limited attention or community debate. Such a role is not only of value for MSP in delivering its activities, but also, in promoting awareness of LSI and related landward agendas more generally, and highlighting the potential value of joined up approaches to action. In distinguishing the importance of such roles for MSP, the findings from 
MSP- LSI project, also suggested that a greater emphasis needs to be placed on MSP, as being an ongoing process of dialogue, discussion, reflection and adaption and not seeing the production of the plan as the conclusion of this process.

The extent to which 'one space' territorial planning approaches are already evident in Europe was revealed by examination of the more general governance arrangements related to spatial planning and LSI in the different case study areas. Although the pattern is highly variable reflecting different country legal and administrative contexts, one of the perhaps more surprising findings was that joined up spatial planning across land and marine areas is by no means new, and is already well established in several European countries.

In Croatia coastal municipalities have long had planning responsibilities out to the edge of territorial waters and a similar position is evident in Germany where coastal Lander have an integrated planning responsibility for the land and sea covering their adjoining territorial waters. It is only beyond the territorial waters that German national government (Bund) has sole responsibility for MSP, although these activities involve close collaboration with the Lander, because many marine activities inevitable pass through Lander space, requiring liaison about coastal environment considerations and/or provision of land based infrastructure when the activities come ashore. Beyond such long established cases, it is evident that the idea of a single territory planning system covering both the land and sea is increasingly being written into primary legislation in European nation states. In the Netherlands, for instance, the 2008 Spatial Planning Act redefined the legal framework for national spatial planning to include the whole of the space over which the government exercised a competence, including the land, territorial waters and out to the edge of their exclusive economic zone. Similarly, in Slovenia, the Spatial Planning Act 2017, which came into force June 2018, envisages an integrated approach where a single body, the Ministry for Environment and Spatial Planning is preparing national spatial documents for both the land and sea, and local coastal municipalities will be required to adopt the MSP as a part of their regional plan. Even in cases where primary legislation separates land and marine planning regimes, the MSP-LSI governance analysis highlighted that being joined-up is being promoted in other ways. Poland is such a case where considerable efforts have been made, through the MSP process, to facilitate a joined up approach through detailed LSI investigations (SCSD PL, 2016).

It is therefore evident that a 'one space' planning perspective is taking root in Europe and that the new era of MSP activity, prompted by the MSP Directive and its LSI requirements, have provided a new impetus to its growth. It is also evident that countries are incorporating 'one space' perspectives in unique ways and that such variations in approach should not only be anticipated but also welcomed. This reflects the fact that individual nation states are at different stages in the 'one space' planning journey and responses to new MSP Directive requirements and the joined up outlook it is encouraging is requiring careful tailoring to mesh with very different existing country contexts. From this perspective and recognizing the exclusive competence over terrestrial planning regimes it would be wrong to try and look at the relative advantages and disadvantages of each approach, but note that innovation is taking place.

\section{Conclusions}

These developments take us back to the opening sections of this paper which charted the search for better governance of coastal and marine areas. Following early experimentation with ICZM, in more recent times, MSP has taken over as the focus of attention and has tended to be seen, by 
many, as the main vehicle for addressing LSI related concerns. However, although it is evident that MSP is making significant strides forward in developing better planning for sea areas within many coastal states, the results of the MSP-LSI project suggest it might be appropriate to consider afresh how far MSP is capable of going beyond a sea-based remit to fully address LSI issues and agendas.

Although it is important to recognize the variability of experience between coastal states, the MSP-LSI study suggests that MSP has relatively limited opportunities to effectively deal with LSI issues on its own and working in isolation. From a maritime sector perspective, this is in part because many, if not the majority of the impacts, effects and needs associated with their LSI are felt on the land, and are therefore beyond the direct scope of MSP. However, by taking a spatialized approach to a value chain analysis to the key maritime sectors that are important to a specific area, the spatial reach and the specific framework conditions shaping a sectors performance can be more systematically considered. Such an analysis can help to highlight where key actors are located and where critical planning interventions may be needed to assist sector development. It must be anticipated that such actors and infrastructure needs may lie well beyond the coastal strip and even beyond national boundaries, in a transnational context, in many instances.

From this, we would argue the process of MSP is just as important as the product, i.e. a plan, which should not be seen as something which is completed at one moment in time, but only part of ongoing process of implementation, monitoring, reflection an adaptation to constantly changing circumstances. Within this MSP process, we would also argue that much greater emphasis needs to be placed on identifying and influencing suitable implementation mechanisms that may fall beyond the narrow scope of MSP or terrestrial planning. Here it may be helpful for MSP implementation efforts to revisit the integration ambitions that ICZM sought to address, to consider how MSP agencies can play a role in encouraging closer inter-sectoral integration (amongst different maritime sectors), intergovernmental integration (amongst levels of government), spatial integration (including LSI), international integration (dealing with transboundary issues), and science-management integration (between disciplines and between science and management/policy).

All this calls for a creative and entrepreneurial form of MSP, and planning more generally. One tentative step in this direction, as suggested in the 'one space' territorial planning concept that guided the development of the MSP-LSI approach (see Fig. 1), is to consider the land and sea, within a country context, as being suitable for 'one space' territorial planning. This might be delivered in a variety of ways reflecting the particular legal, administrative and cultural context of each country. Already there is plenty of evidence to suggest that this level of integration is being practiced in some European member states. Such approaches offer the opportunity to consider land-sea interactions in a more integrated way, within a national context. However, the value chain analysis also highlights that in an increasingly inter-connected world many of the linkages between the land and sea and vice versa are cross-border and transnational in character, requiring 'one space' perspectives that transcend national territorial boundaries as well. The MSP Directive requirements for MSP to consider LSI implications has been instrumental in prompting a new phase of thinking about how best to address the governance of marine and coastal space and has placed MSP at the centre of such deliberations. It will be interesting to see, over the coming years, how far MSP is able to respond in a positive way to this LSI agenda and embrace the creative and entrepreneurial approach to planning that it seems to require. This raises questions about whether too much is being expected of MSP in this respect and whether the LSI debate needs to take another step in a new direction. 


\section{References}

Ballinger, R. (2015). On the edge: Coastal governance and risk. In U., Fra.Paleo (Ed.). Risk Governance. The Articulation of Hazard, Politics and Ecology (pp. 373-394). Dordrecht: Springer.

Cicin-Sain, B., \& Knecht, R.W. (1998). Integrated coastal and ocean management. Concepts and practices. Washington, DC: Island Press.

Douvere, F., \& Ehler, C. (2007). International Workshop on Marine Spatial Planning, UNESCO, Paris, 8-10 November 2006: A summary. Marine Policy, 31(4), 582-583. https://doi.org/10.1016/j.marpol.2007.02.001

Douvere, F., \& Ehler, C. (Eds.) (2008). The role of marine spatial planning in implementing ecosystem-based, sea use management. Special Issue for Marine Policy, 32(5), 759-844.

Douvere, F., \& Ehler, C. (2009a). Ecosystem-based Marine Spatial Management: An Evolving Paradigm for the Management of Coastal and Marine Places. In A., Chircop, S., Coffen-Smout \& M., McConnell (Eds.). Ocean Yearbook (23, pp. 1-26). Boston, Leiden: Brill Academic Publishers.

Douvere, F., \& Ehler, C. (2009b). New perspectives on sea use management: initial findings from European experience with marine spatial planning. Journal of Environmental Management, 90(1), 77-88. https://doi.org/10.1016/j.jenvman.2008.07.004

EC (2017). Land Sea Interactions in Maritime Spatial Planning. Brussels: DG Environment.

Ecorys (2012). Blue Growth Scenarios and drivers for Sustainable Growth from the Oceans, Seas and Coasts. Brussels: Ecorys.

Ehler, C., \& Douvere, F. (2007a). Marine spatial planning: visions for a sea change. Intergovernmental Oceanographic Commission Annual Report 2006. Intergovernmental Oceanographic Commission Annual Report, 13, Paris: UNESCO.

Ehler, C., \& Douvere, F. (2007b). Visions for a Sea Change. Report of the First International Workshop on Marine Spatial Planning. Intergovernmental Oceanographic Commission and Man and the Biosphere Programme. IOC Manual and Guides, 48, Paris: UNESCO.

Ehler, C., \& Douvere, F. (2009). Marine Spatial Planning: a step-by-step approach toward ecosystem-based management. Intergovernmental Oceanographic Commission and Man and the Biosphere Programme. IOC Manual and Guides, 53, Paris: UNESCO.

EC (2014). Directive 2014/89/EU of the European Parliament and of the Council of 23 July 2014: establishing a framework for maritime spatial planning. Official Journal of the European Union L 257/135.

EC (2019). The EU Blue Economy Report, 2019. Luxembourg: Publications Office of the European Union.

EU MSP (2017a). Maritime Spatial Planning: Addressing Land-Sea Interaction: A briefing paper. Brussels: European Commission, DG Mare. Retrieved from https://www.msp-platform.eu/sites/default/ files/20170515_Isibriefingpaper_1.pdf

EU MSP (2017b). Maritime Spatial Planning Conference. Addressing Land-Sea Interactions Conference Report. Brussels: European Commission, DG Mare.

FEC (2018) Our Coastal Futures: A Strategy for the Sustainable Development of the World's Coasts. Future Earth Coasts, Cork. Retrieved from https://www.futureearthcoasts.org/our-coastal-futures/

Glaeser, B. (2008). Integrated coastal management (ICM) between hazards and development. In R.R., Krishnamurthy, B.C., Glavovic, A., Kannen, D.R., Green, A., Ramanthan, Z., Han, S., Tinti \& T.S., Agardy (Eds.). Integrated Coastal Zone Management: The Global Challenge (pp. 279-289). Singapore: Research Publications Services.

Kannen, A., Green, D.R., Glavovic, B.C., Agardy, T.S., Ramanthan, A., Krishnamurthy, R.R., \& Han, Z. (2008). Integrated coastal management (ICM) between hazards and development. In R.R., Krishnamurthy, B.C., Glavovic, A., Kannen, D.R., Green, A., Ramanthan, Z., Han, S., Tinti \& T.S., Agardy (Eds.). Integrated Coastal Zone Management: The Global Challenge (pp. 279-289). Singapore: Research Publications Services.

Kidd, S., \& Ellis, G. (2012). From the Land to Sea and Back Again? Using Terrestrial Planning to Understand the Process of Marine Spatial Planning. Journal of Environmental Policy \& Planning, 14(1), 4966. https://doi.org/10.1080/1523908X.2012.662382 
Kidd, S., Jay, S., Robinson, L., Shaw, D., Jones, H., Pascual, M., Zonta, D., de Vet, J.M., Abhold, K., Kruger, I., McGlade, K., Abdhul Malak, D., \& Sanchez, A. (2020). MSP-LSI - Maritime Spatial Planning and Land-Sea Interactions - Final Report. Luxemburg: ESPON.

Mathews, R. E., Tengberg, A., Sjödin, J., \& Liss-Lymer, B. (2019). Implementing the source-to-sea approach: A guide for practitioners. Stockholm: Stockholm International Water Institute. Retrieved from https://www.siwi.org/publications/implementing-the-source-to-sea-approach-a-guide-forpractitioners/

Morf, A., Cedergren, E., Gee, K., Kull, M., \& Eliasen, S. (Eds.) (2019). Lessons, stories and ideas on how to integrate Land-Sea Interactions into MSP. Stockholm: Nordregio.

OLC (2013). Ocean Literacy: The Essential Principles and Fundamental Concepts of Ocean Sciences for Learners of All Ages Version 2. National Oceanic and Atmospheric Administration.

PDNS (2015). Policy Document on the North Sea 2016-2021. Dutch Ministry of Infrastructure and Environment, Dutch Ministry of Economic Affairs. Retrieved from https://www.government.nl/documents/policy-notes/2015/12/15/policy-document-on-the-north-sea-2016-2021-printversie

Portman, M.E., Dalton, T.M., \& Wiggin, J. (2015). Revisiting Integrated Coastal Zone Management: Is It Past Its Prime? Environment: Science and Policy for Sustainable Development, 57(2), 28-37.

Ramesh, R., Chen, Z., Cummins, V., Day, J., D’Elia, C., Dennison, B., Forbes, D.L., Glaeser, B., Glaser, M., Glavovic, B., \& Kremer, H. (2015). Land-ocean interactions in the coastal zone: Past, present \& future. Anthropocene, 12, 85-98. https://doi.org/10.1016/j.ancene.2016.01.005

Ramieri, E., Bocci, M., \& Marković, M. (n.d.). Land Sea Interactions in the Framework of ICZM and MSP. Venice: CORILA.

SCSD PL (2016). Study of Conditions of Spatial Development in Polish Sea Areas. Gdynia: Maritime Offices in Szczecin, Słupsk and Gdynia. Retrieved from https://www.umgdy.gov.pl/wp-content/uploads/2015/04/inz-msp-study.pdf

Shipman, B., \& Stojanovic, T. (2007). Facts, fictions, and failures of integrated coastal zone management in Europe. Coastal Management, 35(2-3), 375-398. https://doi.org/10.1080/08920750601169659

Small, C., \& Nicholls, R.J. (2003). A global analysis of human settlement in coastal zones. Journal of Coastal Research, 19(3), 584-599.

Smith, H.D., Maes, F., Stojanovic, T.A., \& Ballinger, R.C. (2011). The integration of land and marine spatial planning. Journal of Coastal Conservation, 15(2), 291-303. https://doi.org/10.1007/s11852-0100098-z

Sorensen, J.C., \& McCreary, S.T. (1990). Institutional arrangements for managing coastal resources and environments. Coastal Management Publication No. 1, National Park Service, US Department of the Interior.

Sousa, L.P., Dilasser, J., Ganne, M., Cervera Nuñez, C., Quintela, A., Marques, M., Silva, A., Alves, F.L., Sala, P., Campillos-Llanos, M., Gómez Ballesteros, M., Alloncle, N., \& Giret, O. (2019). Land-sea interactions and relationships with integrated coastal zone management. Northern Atlantic. EU Project Grant Supporting Implementation of Maritime Spatial Planning in the European Northern Atlantic. https://doi.org/10.5281/zenodo.2594720

UN (2016). The First Global Integrated Marine Assessment: World Ocean Assessment I. New York: United Nations.

UNEP (1995). Guidelines for integrated management of coastal and marine areas. UNEP Regional Seas Reports and Studies, 161, Split: United Nations Environment Programme.

UNEP (2006). Marine and coastal ecosystems and human wellbeing: A synthesis report based on the findings of the Millennium Ecosystem Assessment. Nairobi: United Nations Environment Programme.

UNESCO-IOC (2019). Marine Spatial Planning Initiative. Retrieved from http://www.unesco-ioc-marinesp.be/

University of Liverpool (2013). ESTaDOR European Seas Territorial Development Opportunities and Risks: Executive Summary. Liverpool: University of Liverpool.

Zaucha, J., \& Gee, K. (Eds.) (2019). Maritime Spatial Planning, Past, Present, Future. London, Cham: Palgrave Macmillan. 